acute chest infections, including bronchitis, acute otitis media and acute throat infections. He describes the clinical features and complications, the treatment given and the response in terms of short- and long-term prognosis. He discusses critically the pros and cons of tonsillectomy and adenoidectomy as part of the preventive and curative treatment of such children.

A good introductory chapter outlines some of the problems which the catarrhal child presents to those around it-medical, educational and administrative as well as personal. On ætiology several hypotheses are mentioned in each chapter, but at the end of it all, in chapter 10 on 'General Management', the author asks: 'What are we treating?' Here, it must be confessed, he is at his weakest, falling back on the belief that ' most normal children in good health will pass through a phase when colds, coughs, earaches and sore throats are frequent, followed by a phase when they decline and become relatively infrequent '. It is precisely the answer to the vexed question 'Why does this happen to some children and not to others' that is missing from this book on the catarrhal child. None of the several tables and figures show how many children in the practice did not have any or all of these affections during the period of study.

\section{Survey of Research in Gestation and the Develop- mental Sciences}

JACK Davies, M.A., B.SC., M.D. Pp. v +203 . Baltimore: The Williams \& Wilkins Co. London: Baillière, Tindall \& Cox. 1960. 48s.

Based on an analysis of past and current research in the subjects indicated by the title, the book deals firstly with the germ cells, fertilization and implantation of the fertilized ovum.

Placental permeability is discussed in detail and there is an excellent chapter on the chemistry of the developing embryo, genetic factors in development, fœtal endocrinology and physiology, together with an interesting section on fœtal anoxia.

Other chapters deal with teratology, the immunological aspects of pregnancy, parturition and special problems of gestation, including diabetes and toxæmia. There are numerous reference lists.

Throughout the book the author has given his personal criticisms and has indicated on which lines future research may profitably be directed. The reader will appreciate the bewildering complexity of the problems still facing research workers, the methods by which progress is being made and the adjustments in thought made necessary by improved investigational techniques.

The book can usefully be read by all interested in the field of developmental biology.

\section{The Choice of a Medical Career}

Essays on the Fields of Medicine. Edited by JOSEPH Garland, M.D., D.sC., and JosePh STOKes III, M.D. Pp. $x+231$. Philadelphia and Montreal: J. B. Lippincott Company. London: Pitman Medical. 1961. 40s. (\$5).

- This volume comprises 2 I original essays by distinguished medical teachers of experience in the United States and Canada. Although these are, presumably, intended primarily for American and Canadian readers they contain little if anything that is not equally suitable for English students, who will find in them much wisdom and excellent counsel. In the Preface the Editors remind us that 'despite all the ramifications that medicine has undergone and the sweet uses of its diversity, most of which has been in the name of progress, one must still remember that the single purpose of the profession is the prevention of disease, and the care of those who are ill'. (Our italics.) This, indeed, gives us the leit-motif of this excellent book.

It is with no desire to make invidious distinctions between individual essays that we call special attention to the first chapter, which gives a fair and judicial estimate of the position which confronts those entering the medical profession today. Prof. Burwell makes clear the responsibility which rests upon student and teacher alike to maintain a proper appreciation of the blend of science and art which makes up the complex of modern medicine. The general trend of his essay is reflected in those of his fellow-contributors. Some of these will, of course, have a greater appeal than others, according to the particular needs of individual readers; but all are carefully prepared, and each has a helpful and important message to convey.

The volume concludes with a very fine and inspiring address entitled 'Caritas Medici', which greatly impressed us, and for which we cannot refrain from a special word of admiration.

To review this book has been a pleasure, and we cordially recommend it to our readers.

\section{Problems of the Physiology of the Processes of Fatigue and Recovery}

Various authors. Academy of Sciences of the Ukrainian S.S.R., Kiev, 1958. Pp. vii +264 . Translated from the Russian. Published for the National Science Foundation, Washington D.C., and the Department of Health, Education, and Welfare, by the Israel Programme for Scientific Translations. 1960. 60s.

With Russians leading in the race for the moon and making remarkable progress in athletics, we plunge into this book eagerly prepared to learn their ways. Unfortunately it is extremely heavy going; bits of information can be gathered here and there, but much is hid in darkness. Although it is usually possible to make out the meaning of any one sentence, the translation is appalling and adds a great deal to the labour of reading the book. After a while the suspicion develops that it has all been done by a machine. A short sentence may be quite easy: "The idea was to ligate in the presence of a fistula of the bile cyst, the common biliary duct, not where it falls into the duodenum, but between two liver passages'. However, in the more involved sections, particularly in those dealing with conditioned reflexes, the combination of Russian thought and Russian exposition served up in most peculiar English presents difficulties which will deter all but the most stalwart.

The field is wide, and there are 25 sections, each by a different author, on topics such as the trophic influence of the nervous system, fatigue and recovery in various organs, cortical changes during muscular activity, fatigue of salivary secretion, changes in the Nissl substance during fatigue and recovery, etc. The work as a whole is related to the concept of conditioned reflexes and to the control of physiological processes by the nervous system.

A very large proportion of the experiments described involve very simple measurements, such as the amount of saliva secreted, reaction times, blood pressure, etc., and only a minority incorporate recent methods. Now that micro-electrode, histochemical and other modern techniques are developing rapidly in the Soviet Union, it is unfortunate that so few recent references are given; hardly any are later than 1956 , and in his section, A. P. Kovtun, apart from referring to two books by Pavlov, gives no reference more recent than 1912. The Russian 
edition was 'signed for printing' in 1958, and the English translation published in 1960.

There are occasional tantalizing glimpses of something new. We learn that 'If the state of any internal organ changes ... then the electrical potential of a certain point on the skin, which is probably related to this organ, changes sharply ... A. K. Podshibyakin ... showed the possibility of acting from these points on the internal organs. The work in both directions continues with great success today in a number of clinics in Kiev'.

'A great number of active points which we determined concur with the points of the skin which are used in Chinese popular medicine ... They use these points for therapeutic action on the internal organs by applying needles and cauterization (method of chen-tsiu therapy)'.

The section on 'Active Rest' by I. V. Muravov is interesting in a very Russian way. Sechenov found, and Russian physiology textbooks report that if an ergograph is operated with one hand, then recovery from fatigue will take place more rapidly if work is carried out by the other hand during a rest pause. Muravov reports that under certain conditions the reverse effect may occur, and active rest may hinder instead of help recovery. The effect may be very striking: for example, after taking $1.0 \mathrm{~g}$. of $\mathrm{NaBr}$ and resting passively, the amount of work done was 121.29 units, but after taking the same amount of $\mathrm{NaBr}$ and resting actively the amount of work done was only 39.00 units. 'More than two thousand experimental tests were made on 27 subjects, and 300 clinical examinations on 25 patients suffering from disturbances of the motor function'. From the point of view of the reader, this labour was wasted. In the example quoted, there is no means of telling if it was one freakish result or the mean of 2,000 tests on 27 subjects.

Some of the references are puzzling. Consider: 'Sherrington, Ch., Kread, R., Denni-Brown, D. Ixel, I., Liddel, E., Reflectory Activity of the Spinal Cord/Translated from the Russian/, 1935'. Odd. Another is rather enticing: "Tramble, A., Memoirs to the History of One Species of Fresh Water Polyps with Hands in the Shape of Horns, 1937'.

Let us hope that other up-to-date Russian collections of this type will be translated promptly, and by a live physiologist whose native language is English.

\section{Modern Treatment Yearbook, I96r}

Editor: Sir Cecil Wakeley, BT., K.B.E., C.B. Pp. xviii +310 , illustrated. London: The Medical Press. 196r. 35s.

This book is a compendium of 31 chapters by different authors, on subjects as diverse as polycythæmia and urethral stricture, breech presentation and conjunctivitis. The style, in general, is didactic, each author giving a résumé of currently accepted methods of treatment.

No single reviewer can assess the validity of all the diverse information supplied, but those subjects familiar to this reviewer were well presented and up to date, although rather superficial, which is, perhaps, inevitable in such short articles.

The chief difficulty about the book lies in deciding to whom to recommend it. The senior student and the newly-qualified doctor should get most value for their thirty-five shillings.

\section{Principles of Medicine: An Integrated Textbook} for Nurses

JAMES Verney CABle, M.D., M.R.C.P., F.R.A.C.P. Pp. vi +661 , illustrated. Christchurch, New Zealand: N. M. Peryer. I960. 55 s.

The key to this book is given by the author in his preface when he states: 'I am satisfied that the student nurse of today deserves to be provided with something better than a mere recital of facts. Few are content with being taught that such and such an event occurs in disease-they want to know why; and throughout the book I have endeavoured, as far as possible, to meet this need'

He has succeeded admirably in his aim, because this is a readable book which covers the whole of internal medicine in an interesting way. The information contained in it is accurate and up to date, so that its readability is matched throughout by useful knowledge. It can be warmly recommended.

\section{Concepts of Medicine}

A Collection of Essays on Aspects of Medicine. Edited by Brandon Lush, M.D., M.R.C.P. Pp. $x+286$, illustrated. Oxford, London, New York and Paris: Pergamon Press. 1961. 50s.

This anthology brings together broad philosophies of 19 distinguished British and American doctors.

The three sections of the book comprise concepts of medicine; concepts of health and of disease; and concepts of medical research. The editor's choice is catholic for we learn the views of a Welsh country practitioner, a London family doctor, a medical editor, consulting physicians, research workers, and professors of medicine, pathology and physiology.

One of the aims of the book is to provide medical students with a wider vista than the immediate demands of their medical curriculum. This has been accomplished fluently, but it is unlikely to be appreciated by them until they reach their postgraduate years. To all postgraduates, it is recommended bedside reading. They may not wholly approve of the editor's selection, which is after all a personal one, but it should provide a stimulus to further thought and perhaps self-analysis of the reader's own concepts.

\section{Tobacco: Experimental and Clinical Studies}

P. S. Larson, PH.D., H. B. HaAg, M.D., and $H$. SylvetTe, Ph.D. Pp. xii +92 I + index. Baltimore: The William and Wilkins Company. London: Baillière, Tindall and Cox. 1961. 160s.

This monograph on tobacco weighs over five pounds and contains 932 pages. It has taken three professors of pharmacology 20 years to produce for they have read and abstracted over 6,000 articles appearing up to 1959 in 1,200 journals. The bibliography occupies 109 pages and each page is of three columns. The authors indicate that it is not the last word on tobacco but only on the millions which have been written so far. In making their claim that it is a truly exhaustive source of references to the world's literature, they ask the generous reader with defiance, tinged with some poignance, to let them know of any references thcy may have overlooked. It would be churlish to do so, however, when it is realized that they have already devoted a cumulative total of some 50 years' interest in the biological and medical effects of tobacco. As though mesmerized by the massive data accumulated, the authors decided to be non-selective, and th:s draw attention to good work and bad, sound and uninformed opinions alike in the same size type. Because of this inability. to be discerning, the quality of the work inevitably suffers.

The authors are to be congratulated on their painstaking endeavours but not for forsaking quality for quantity. It is hoped that they will now produce a more balanced, readable and authoritative account of the subject. 